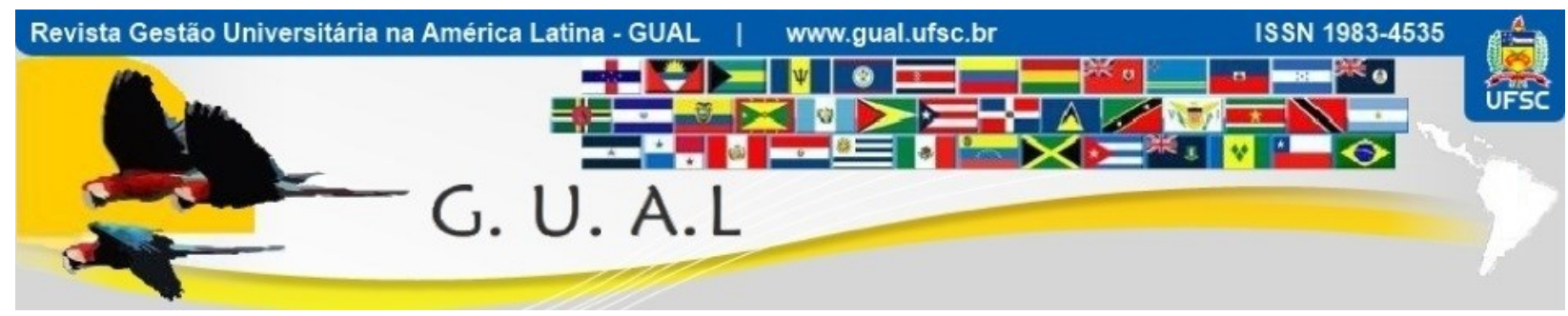

DOI: http://dx.doi.org/10.5007/1983-4535.2019v12n1p49

\title{
O SIGNIFICADO DA GESTÃO PARA OS COORDENADORES DE CURSO SUPERIOR
}

\section{MEANINGS OF THE MANAGEMENT CONCEPT IN THE SUPERIOR COURSE COORDINATORS}

Tainá Rodrigues Gomide Souza Pinto, Doutora
https://orcid.org/0000-0001-8142-0047
tainagomide@yahoo.com.br
Universidade Federal de Viçosa | Departamento de Administração e Contabilidade
Viçosa | Minas Gerais | Brasil
Simone Martins, Doutora
https://orcid.org/0000-0002-6614-4811
simmone.martins@gmail.com
Universidade Federal de Viçosa | Departamento de Administração e Contabilidade
Viçosa | Minas Gerais | Brasil
Renaldo de Faria, Bacharel
https://orcid.org/0000-0001-8707-0041
renaldo.faria@ufv.br
Universidade Federal de Viçosa | Departamento de Administração e Contabilidade
Viçosa | Minas Gerais | Brasil

Recebido em 28/março/2017

Aprovado em 05/novembro/2018

Publicado em 02/janeiro/2019

Sistema de Avaliação: Double Blind Review

Esta obra está sob uma Licença Creative Commons Atribuição-Uso. 


\title{
RESUMO
}

O objetivo do presente estudo descritivo é compreender os significados e as características da gestão para os coordenadores de curso superior de uma universidade federal de Minas Gerais. Para tanto, foram utilizados como base os ensinamentos de Henry Mintzberg (2010). Para a coleta de dados foram realizadas entrevistas semi-estruturadas e para a sistematização dos resultados a técnica análise de conteúdo. Verificou-se que os coordenadores compreendem a gestão de curso superior como o ato de gerenciar o seu projeto pedagógico, como a articulação existente entre os alunos e a administração superior da universidade e como o processo burocrático e de organização que envolve o curso. Dentre as características observadas, ritmo acelerado, no qual as atividades são variadas e desenvolvidas de forma fragmentada. Enfrentam desafios ao lidar com a falta de recursos materiais e humanos e com a falta de uma política de capacitação para o cargo. Também de conciliar as atividades de gestor com as demais atividades da carreira docente, sem que se observe uma política de incentivo. Conclui-se que embora o coordenador esteja gerindo a formação do profissional do futuro, se encontra solto numa estrutura burocrática e política, reagindo às ações e não agindo estrategicamente.

Palavras-chave: Gestão. Gestão Universitária. Coordenação de Curso Superior.

\begin{abstract}
The purpose of this study is to understand the meanings of management held by the coordinators of higher education of a federal university of Minas Gerais. It is based on the teachings of Henry Mintzberg (2010). For data collection, semi-structured interviews were carried out, and the results were systematized with the help of content analysis techniques. It was verified that the coordinators understand the management of the advanced course as the act of managing their pedagogical project; as the existing articulation between the students and the superior administration of the university and as the bureaucratic and organization process that embeds the course. Among the observed characteristics, what stands out is an accelerated rhythm, in which varied activities are developed in a fragmented way. Coordinators face challenges in dealing with the lack of material and human resources and the lack of a job training policy. Also the challenge of conciliating the managerial activies with the other activities of the teaching career, with no incentive policy in sight. The article concludes that although the coordinator is managing the training of future professionals, she is left alone in a bureaucratic and political structure, in which she reacts to actions but doesn't act strategically.
\end{abstract}

Keywords: Management. University Management. Higher Education Coordination. 


\section{INTRODUÇÃO}

Henry Mintzberg publicou em 1973 um livro sobre a natureza do trabalho gerencial, seus apontamentos foram baseados em um estudo intensivo realizado para entender o trabalho gerencial de cinco executivos. Com base nesta pesquisa, Mintzberg formulou suas ideias de funções gerenciais e indicou proposições acerca das características da gestão.

Alguns anos se passaram e, em 2010, Mintzberg publicou a obra intitulada Managing: desvendando o dia a dia da gestão. $\mathrm{O}$ autor apresenta nesse estudo a ideia de que a gestão não tem mudado ao longo dos anos, que o significado e as características da gestão dos dias atuais são as mesmas das que foram constatadas em 1973. Para o autor, a gestão dos dias atuais, apesar das inovações tecnológicas e de todo o processo de desenvolvimento, de todo o modismo em torno da liderança, mantém as mesmas características da gestão do passado, se curvando ao ritmo implacável, a brevidade e variedade das atividades, a fragmentação e descontinuidade do trabalho, a orientação para a ação, a preferência por modos informais e orais da comunicação, a natureza literal do trabalho, ao controle no trabalho. Ou seja, assim como em 1973, a gestão ainda ocorre em um ritmo acelerado o que dificulta o planejamento e a reflexão do trabalho.

O gerente se encontra em um ritmo acelerado e as práticas de gestão parecem indicar um processo de desconstrução do próprio gerente. No entanto, a tarefa de gestão deve compreender que o ser humano busca sentido às suas ações. A gestão deve ser vista como uma atividade social, na qual o contexto e a historicidade são fatores importantes, que não podem ser apreendida sem ser vivenciada e que todo significado atribuído depende de como somos. Dessa forma, não deveria existir uma única forma de gerenciar, nem um único significado, sendo difícil pensar em modelos universais. Na prática, a forma de gerenciar é particular, dependente do contexto e da experiência do próprio gestor.

Estudos indicam a relevância das práticas de gestão nas universidades para que essa consiga atingir o objetivo de fornecer um bom serviço de formação superior, sendo importante a identificação e análise das características gerenciais dos gestores de todos os níveis (MARRA，2005; CAMPOS，2007; MAGALHÃES，2010; SANTANA， 2010; ESTHER, 2011; GOMES, 2013). Os referidos estudos concluíram que os ocupantes de cargos de gerentes nas universidades enfrentam dificuldades ao assumirem a gestão (GOMES, 2013). Assim, os ensinamentos de Mintzberg (2010) que apontam para as limitações da atuação dos gerentes chamam a atenção para um novo olhar para as organizações. 
O livro de Mintzberg inspirou o presente estudo, uma vez que, considerando que a forma de agir dos coordenadores de curso superior provavelmente difere entre eles de acordo com os seus sentimentos e suas crenças, sua vivência prática ou acadêmica e as influências que carregam em um ou outro tipo de formação, acredita-se que seria interessante revelar nesta pesquisa a atribuição de significado e de características da gestão que é particular aos coordenadores de curso superior. Assim, o objetivo deste estudo é compreender os significados e as características de gestão para os coordenadores de curso superior de uma universidade federal de Minas Gerais. Para tanto, serão utilizados como base os ensinamentos de Henry Mintzberg no que diz respeito à gestão.

Homberg e Tyrstrup (2010) alertam para o fato de que os estudos sobre o trabalho gerencial têm focado mais nas questões objetivas e nas suas causas, e que a pesquisa sobre trabalho gerencial tem negligenciado sistematicamente a ligação entre as ações do indivíduo e sua compreensão das atividades organizacionais. Os autores consideram que na agenda das pesquisas gerenciais tem ocorrido uma forte tendência em colocar o líder no centro das investigações, assim, o contexto e a dinâmica das práticas de gestão tem sido deixadas de lado. Consideram, ainda, a necessidade de estudos que coloquem o dia a dia do trabalho gerencial, a criação de significado e de sentido no centro do "palco".

Dessa forma, pode-se verificar que esta pesquisa se torna relevante, pois há pouco estudo sobre a percepção dos coordenadores de curso superior diante das funções que desempenham enquanto gerentes. Até o momento as pesquisas apontaram para as características e competências que os gerentes possuem e devem adquirir. Portanto, esta pesquisa se justifica pela necessidade de se conhecer como o gerente, mais especificamente o coordenador de curso, enquanto sujeito se sente em relação aos novos desafios gerenciais.

Para o desenvolvimento dessa proposta de pesquisa, a mesma está estruturada, além desta introdução, em outras quatro seções. A primeira contendo uma breve revisão de literatura sobre a coordenação de curso superior e a gestão. $\mathrm{Na}$ segunda seção, serão apresentadas as reflexões de Mintzberg (2010) no que diz respeito ao significado e as características da gestão. Na terceira seção, serão apresentados os procedimentos metodológicos para a realização da pesquisa. Posteriormente, na quarta seção, uma expectativa de apresentação dos resultados a serem encontrados será indicada. 


\section{O COORDENADOR DE CURSO SUPERIOR E A GESTÃO}

O estilo de gestão burocrática é o predominante nas universidades, segundo Reis (2011). Os profissionais que ocupam o cargo de gerente nas instituições de ensino superior não conseguem identificar claramente os objetivos a serem alcançados, são influenciados por considerações políticas, por grupos de interesses nas tomadas de decisão e não tem um procedimento de avaliação delimitado (REIS, 2011). Entretanto, os gerentes universitários tem percebido a necessidade de mudar essa concepção de gestão, sendo necessário o desenvolvimento de competências gerenciais (SILVA, 2009). Ocorre que na prática, o ambiente universitário tem enfrentado dificuldades no processo de adaptação gerencial por parte dos professores que assumem alguma função de gerente, uma vez que esses ainda estão presos ao estilo burocrático e não possuem qualificação especifica para as práticas gerenciais (GOMES, 2013).

O que se pode observar nas instituições de ensino superior, é que elas possuem estruturas organizacionais específicas em que pessoas, em diversos níveis, desempenham seus papéis de acordo com o delineamento organizacional proposto. De acordo com Alvez (2009), nas instituições de educação de nível superior, os coordenadores de curso atuam como gerentes em um nível intermediário, executando funções, tarefas e atividades que requerem a mobilização de diversos conhecimentos, habilidades e atitudes, tais como: formação acadêmica na área específica, competências inerentes às funções administrativas para a gestão de processos organizacionais e acadêmicos, competência para interpretar a legislação educacional, competência didático-pedagógica, conhecimento das tecnologias e métodos importantes ao gerenciamento educativo e competência comportamental necessária ao desenvolvimento das relações interpessoais. (ALVEZ, 2009)

Para Marcon (2008, p. 23), “a coordenação de um curso de graduação é uma função administrativa com dimensões acadêmicas, pedagógicas e científicas no campo profissional correspondente ao curso". O autor acredita que o desenvolvimento do curso de graduação, bem como a qualidade das intervenções dos egressos desses cursos, é resultado da ação conjunta do coordenador de curso, dos ocupantes dos cargos da alta administração, dos docentes e dos órgãos auxiliares da instituição. Neste sentido, necessário se faz que o coordenador consiga articular as várias atividades da unidade que coordena, em especial, as desenvolvidas pelos docentes, discentes e técnicos administrativos. 
No contexto das instituições de ensino superior constitui-se como prática o fato de docentes passarem a assumir o papel de gestores e exercer atividades administrativas por indicação ou eleição, sem que os mesmos tenham capacitação específica para essa função (MARCON, 2008). Meyer (1998) argumenta que é comum, principalmente nas universidades públicas, a preponderância da figura do "gestor amador". Seguindo essa mesma linha, Zabalza (2004) afirma que os dirigentes, nesse tipo de instituição, orientam suas ações de acordo com as demandas e define sua atuação como amadora. Batomé e Kubo (2002) acreditam que os gestores nas instituições públicas de ensino superior são mais "decretados” do que preparados para exercerem a função de gestão, visto que muitos são nomeados sem ter conhecimento de como gerir.

As principais formas de acesso à coordenação de curso, segundo Viana (2006), são o convite, a indicação e a eleição. O autor indica também que, no momento da escolha a capacidade gerencial não é uma exigência para assumir o cargo de coordenador de curso, sendo a experiência profissional a característica mais levada em consideração no momento da escolha.

Ahmad (1994) realizou um estudo com o objetivo de identificar as formas de aprendizagem adotadas por diretores de universidades americanas no exercício de suas funções. O resultado da pesquisa é que a principal forma de aprendizagem da função de gestor são as práticas informais, tais como, replicar as ações de outros gestores, tentativa e erro, observar e ouvir colegas, dentre outras. O autor conclui, então, que a aprendizagem da atividade de gestão dos dirigentes de universidades ocorre durante a ação e exercício da função. A ação gerencial é desenvolvida pelos coordenadores de curso, em geral, pela adoção de práticas informais em que a experiência, as rotinas e a burocracia das instituições se tornaram os mecanismos de aprendizagem gerencial do coordenador.

Neste mesmo sentido, Reesor (1995) argumenta que os docentes que ocupam o cargo de gestores, em sua maioria, nunca haviam planejado ocupar um cargo de gestão dentro da instituição e que o fizeram por indicação dos departamentos ou dos conselhos, e que desenvolveram as características de gestão durante o exercício da função e de forma autodirecionada. É interessante notar que, geralmente, as atribuições acadêmicas são predominantes em detrimento das não acadêmicas, sendo as funções gerenciais, políticas e institucionais relegadas (PALMEIRAS e SZILAGYI, 2011).

Camargos (2010) indica que as principais atividades cotidianas realizadas pelos coordenadores de curso são as atividades voltadas para a integração e inserção do curso na 
sociedade; atividades ligadas ao corpo docente, atividades voltadas aos alunos; atividades essencialmente pedagógicas e administrativas. É possível identificar que são várias as atividades desenvolvidas pelo professor que assume um novo papel na instituição de ensino superior, o papel de gerente.

Apesar das limitações dos professores universitários no que diz respeito às atividades da coordenação de curso, propõe-se neste trabalho voltar o olhar para o significado e as características da gestão, por considerá-las importantes reflexões que ajudarão na prática gerencial dos mesmos. Dessa forma, no próximo tópico o significado e as características da gestão serão tratados mais especificamente sobre a proposição de Mintzberg (2010).

\section{O SIGNIFICADO E AS CARACTERÍSTICAS DA GESTÃO}

A gestão está inserida em todos os ambientes da sociedade, seja em casa, na escola, na igreja ou em outros tipos de organização. Kwasnida (2009) afirma que a gestão não está presente somente nos setores produtivos de bens e serviços, e sim que a mesma se faz presente em todos os diferentes modos de produção, nos diversos momentos da história e em todas as formações sociais. Mintzberg (2010, p. 16) enfatiza que a "gestão é muito importante para qualquer um que seja afetado por sua prática, o que em nosso mundo de organizações significa todo mundo".

Durante as últimas décadas muitos estudos foram publicados enfatizando a importância da liderança nas organizações (HALES, 2002 apud TENGBLAD, 2006), apresentando na maioria das vezes, uma visão pós-burocrática. A visão pós-burocrática pode ser entendida como a ideia de organização flexível e não hierarquizada, construída a partir de valores comuns, de diálogos e da confiança. A ideia é que o novo papel do gestor seria o de facilitador para que os funcionários habilitados resolvam os problemas por si mesmos, por meio de redes. (TENGBLAD, 2006)

Ocorre que essa visão do novo trabalho gerencial não tem sido comprovada na prática, uma vez que os estudos empíricos realizados com gerentes de nível intermediário revelam que ocorreram apenas pequenas mudanças no comportamento gerencial, mais especificamente no que diz respeito à fragmentação das atividades e do tempo (TENGBLAD, 2006). O que se percebe é que essa nova visão de liderança está em contraste com a tradição do trabalho gerencial que retrata como os gerentes são altamente reativos em suas ações (HOMBERG e TYRSTRUP, 2010). 
Uma vez que a literatura sobre o trabalho gerencial é extensa, um enquadramento teórico se faz necessário. Neste sentido, o estudo do trabalho gerencial de Henry Mintzber (2010) é bem conhecido. Mintzberg (2010) em seu livro Managing: desvendando o dia a dia da gestão, publicado em 2010, apresenta a ideia de que a gestão não tem sofrido grandes mudanças, que os gerentes têm trabalhado nos dias atuais da mesma forma que trabalhavam anos atrás, assim, questões como tecnologia, flexibilidade, globalização e pressões competitivas não exercem influências significativas na prática gerencial (TENGBLAD, 2006).

Mintzberg (2010) inicia sua obra com uma questão interessante no que diz respeito aos gerentes e a gestão. O autor propõe a seguinte reflexão aos gerentes: "o que aconteceu no dia em que você se tornou um gerente?". A resposta é que os gerentes aprendem pela experiência o que significa ser um gerente. "A gestão não é uma ciência nem uma profissão; é uma prática, aprendida principalmente com a experiência e enraizada no contexto." (MINTZBERG, 2010, p. 23)

Mintzberg (2010) acredita que a gestão não é uma ciência, mas que certamente a gestão utiliza a ciência, uma vez que os gerentes precisam acumular o máximo de conhecimento possível, e que devem utilizar as análises baseadas no conhecimento científico. $\mathrm{O}$ autor defende que a gestão depende mais da arte, que essa produz compreensão e visão, baseada em intuição. É interessante notar que, na prática, a gestão ocorre na medida em que os gerentes enfrentam as questões e os problemas. Dessa forma, características como experiência, intuição, juízo e sabedoria são necessárias para o entendimento do significado da gestão.

As formas de aprendizagem dos ocupantes de cargos de gestão nas instituições de nível superior encontradas refletem o pensamento que Mintzberg (2010), uma vez que esse acredita que na gestão existe muito conhecimento tácito, e que esse significa que a aprendizagem ocorre durante a prática do trabalho, por meio de mentorado e experiência direta. $\mathrm{O}$ autor acredita que nesse processo de aprendizagem o contexto é muito importante, o que significa que a aprendizagem em gestão não é facilmente transferível entre posições gerenciais e entre organizações. Sendo necessário para a função de gerente o conhecimento do contexto específico, e que as tomadas de decisão sejam realizadas com base nesse contexto.

As várias atividades exercidas no cotidiano de uma coordenação de curso são compatíveis com as características de gestão apontadas por Mintzberg (2010). Mintzberg descreveu as características da gestão pela primeira vez em 1973, o que nos leva ao pensamento de que a prática da gestão não mudou muito até os dias de hoje. $\mathrm{O}$ autor ressalta o 
mito que existe em torno das características da gestão, classificando-o como folclore as ideias de que o gerente exerce a sua atividade planejando, organizando e controlando.

Mintzberg (2010) aponta que vários estudos identificaram que os gerentes trabalham em um ritmo acelerado, no qual suas atividades são variadas, desenvolvidas brevemente e de forma fragmentada. O ritmo gerencial intenso é explicado pela sua natureza inerentemente aberta, não sendo possível identificar o momento em que se dá o encerramento do trabalho gerencial. No que se refere a característica intrínseca à atividade gerencial, a sua natureza fragmentada, as interrupções são constantes durante as tarefas, sendo essas, muitas das vezes, desejadas pelos gerentes que acreditam que dessa maneira não desencorajem o fluxo de informações atualizadas. Um risco ocupacional do trabalho gerencial é o risco de ser superficial, uma vez que a atividade de gestão está marcada pelo ritmo intenso e pela fragmentação, pode acontecer de que as decisões sejam tomadas sem a reflexão profunda necessária. (MINTZBERG, 2010).

Outra característica da atividade gerencial é a orientação para a ação. As atividades mais tangíveis, que rementem à concentração no que é mais concreto são típicas do trabalho de gestão. As reflexões e os planejamentos ficam em segundo plano. Segundo Mintzberg (2010), todos os gerentes planejam, mas tal fato não os transforma em planejadores sistemáticos. Dessa forma, o planejamento ocorre implicitamente no contexto das ações diárias dos gerentes.

Nesse mesmo sentido, Ghosgal e Bruch (2003) acreditam que o trabalho do gerente deve envolver a volição, sendo essa a vontade em realizar ações, o entusiasmo que o gerente deve possuir ao realizar suas atividades. Entretanto, essa orientação para a ação de forma entusiasmada não deve ser vazia de reflexão, existindo ai um perigo, que é o risco de que compromissos profundos sejam feitos às pressas. Ghosgal e Bruch (2003) alertam para o fato de que os gerentes devem primeiramente se ausentarem do trabalho para refletirem.

Em termos de comunicação, os gerentes têm uma tendência a preferirem os meios informais, mais especificamente as informações que são repassadas por telefone, por email e por reuniões. Mintzberg (2010) enfatiza que, ao contrário de outros profissionais, o gerente não abandona o telefone, as reuniões e os emails, por considerar esses o seu trabalho. Os gerentes, normalmente, dão muita atenção às informações que chegam para eles por meio de fofocas, boatos e especulações. Eles acreditam que a fofoca de hoje pode ser o fato de amanhã, como os gerentes querem obter as informações o mais rápido possível, então esses meios, ainda que duvidosos, são levados em consideração. Ghosgal e Bruch (2003) destacam 
que as organizações estão repletas de "sirenes", sendo essas distrações que podem tirar a atenção do gerente e fazer com que esse perca o seu objetivo. Alguns gerentes tentam tornar os seus ambientes impermeáveis às sirenes, entretanto, Mintzberg (2010) considera que as "sirenes" são bem vindas, sendo desejável que o fluxo de infomações esteja sempre aberto.

Outro aspecto da comunicação na atividade de gerente é a importância do acesso pessoal. Segundo Mintzberg (2010), é importante que o gerente conheça pessoalmente o lugar e as pessoas com quem está lidando, pois, com o acesso pessoal direto, a comunicação ocorre de forma mais eficaz do que quando o trabalho ocorre à distância. O autor acredita que, mesmo em um mundo globalizado, o trabalho do gestor ainda deve ser realizado de forma mais local e pessoal. E, por consequência desse contato pessoal, os gerentes podem ser considerados verdadeiros bancos de dados, por possuírem informações que a vivência do dia a dia proporciona.

A relação lateral entre colegas é outra característica marcante do trabalho do gerente. O gerente lida com uma ampla variedade de pessoas, sendo clientes, fornecedores, sócios, funcionários do governo e do setor, assim, pode-se considerá-lo como uma "ampulheta, por estar posicionado entre uma rede de contatos externos e a unidade interna administrada. $\mathrm{O}$ gerente recebe todo o tipo de informações e pedidos de pessoas de dentro e de fora" (MINTZBERG, 2010, p. 43).

Mintzberg (2010) considera que o pensamento de que o gerente tem o controle rígido das atividades é um folclore, pois na prática o que se observa é que o controle é realizado dentro do possível, e de forma implícita. O autor conclui que o gerente consegue exercer o controle, apesar das limitações, por adotar dois tipos de atitudes com grau de liberdade, ou seja, eles tomam decisões que definem os seus compromissos subsequentes e adaptam para seus próprios interesses atividades que são obrigados a realizarem. Assim, os gerentes criam algumas situações e tiram vantagens de outras.

Diante de todo o exposto, pode-se verificar que as características da gestão consideradas por Mintzberg (2010) são: o ritmo acelerado, a brevidade, a variedade e a fragmentação das atividades, as interrupções, a orientação para a ação, o aspecto informal da informação, a natureza lateral das relações, e o controle implícito. Entretanto, o autor adverte que esse conjunto de características não indica que o que ocorre é uma má gestão. Esse é o cenário inevitável do trabalho gerencial, sendo considerável normal.

Assim, a despeito das limitações existentes em relação à atividade gerencial e considerando a importância do significado e das características da gestão, propõe-se trazer 
para o contexto dos coordenadores de curso superior a reflexão sobre a gestão. Para tanto, os procedimentos metodológicos serão apresentados no tópico seguinte.

\section{PROCEDIMENTOS METODOLÓGICOS}

De modo a alcançar os objetivos propostos, o estudo se baseia em uma abordagem qualitativa, uma vez que, para essa o ponto de vista dos sujeitos é especialmente importante, que o ambiente é a fonte dos dados e que o pesquisador é instrumento-chave de análise (BOGDAN \& BIKLEN, 1994). Flick (2009) traz ainda que esta abordagem tem como objetivo entender, descrever e explicar os fenômenos sociais. Podendo assim analisar experiências de indivíduos ou grupos, examinar interações e comunicações que estejam se desenvolvendo, buscando entender codificar como as pessoas constroem o mundo a sua volta.

Quanto ao objetivo a presente proposta se classifica como descritiva, pois, segundo Gil (2002), essa tem como finalidade primordial a descrição das características de determinada população ou fenômeno.

Para a coleta de dados foram realizadas entrevistas semi-estruturadas com onze dos quinze coordenadores de curso que atuam na área de Ciências Humanas e de Ciências Sociais Aplicadas de uma universidade federal.

O conteúdo das entrevistas com os coordenadores de curso da universidade em questão foi tratado pelo método da análise de conteúdo. Bardin (1977) define a análise de conteúdo como uma técnica que visa obter por procedimentos sistemáticos e um conjunto de técnicas de analise das comunicações visando obter, por procedimentos sistemáticos e objetivos de descrição do conteúdo das mensagens, indicadores (quantitativos ou não) que permitam a inferência de conhecimentos relativos às condições de produção/recepção (variáveis inferidas) destas mensagens. Utilizando-se dessa técnica, as respostas às perguntas que compuseram as entrevistas foram classificadas e agrupadas de acordo com as variáveis e constructos que se desejou estudar. As respostas foram transcritas; apresentadas em categorias para análise e, posteriormente, interpretadas.

\section{ANÁLISE DOS RESULTADOS}

Para melhor entendimento do significado e das características da gestão para os coordenadores de curso superior, buscou-se identificar, junto aos entrevistados, a compreensão que os mesmos possuem sobre gestão e quais são as características da gestão que os mesmo praticam, tendo como base teórica os ensinamentos de Mintzberg (2010). 
Diante do objetivo proposto, foram construídas quatro dimensões para a realização da Análise de Conteúdo.

A primeira categoria analisada é Característica dos Coordenadores de Curso Superior, a segunda é Desafios dos Gestores na Coordenação de Curso Superior, a terceira é a do Significado da Gestão para os Coordenadores e a quarta é a da Características da Gestão, na Percepção dos Coordenadores .

As primeiras três categorias de análise têm como objetivo identificar o perfil e as características dos ocupantes do cargo de gestão dos cursos superiores e identificar a compreensão que eles possuem sobre a gestão. Mintzberg (2010) acredita que os gerentes aprendem pela experiência o que significa ser um gerente, dessa forma, para melhor compreensão do significado da gestão para os coordenadores de curso, se fazem necessárias, além da categoria que trata da sua compreensão efetivamente, as dimensões que tratam do perfil e da característica dos coordenadores; e dos desafios que os estes enfrentam na gestão de curso superior.

A quarta categoria de análise estudada é Características da Gestão, na Percepção dos Coordenadores, que envolve sete subcategorias; esta procura identificar se as características da gestão apontadas por Mintzberg (2010) ocorrem efetivamente na prática da gestão dos coordenadores de curso superior. As quatro categorias são apresentadas, detalhadas e discutidas, uma a uma, nos tópicos a seguir.

\subsection{CARACTERÍSTICAS DOS GESTORES NA COORDENAÇÃO DE CURSO SUPERIOR}

A categoria de análise 'Características dos Coordenadores de Curso Superior' tem como objetivo categorizar as características dos coordenadores de curso para verificar como essas influenciam na sua concepção sobre gestão.

Pode-se verificar, a partir das entrevistas realizadas, que as concepções de Mintzberg (2010) - de que o significado de ser um gerente os gerentes aprendem pela experiência - é confirmada na prática da gestão de curso superior, uma vez que, a maioria dos coordenadores entrevistados afirma não possuir formação em gestão, com exceção de dois coordenadores que possuem formação superior em administração. De acordo com os entrevistados, a formação do coordenador como gestor do curso ocorre efetivamente no dia a dia da função, uma vez que não passam por processos de treinamento para o cargo de coordenador de curso. Os entrevistados apontam a falta de treinamento para exercer o cargo como um desafio. 
Marcon (2008), Meyer (1998), Zabalza (2004) e Batomé e Kubo (2002) identificaram em seus estudos o que foi constatado nos dados da presente pesquisa, ou seja, para os referidos autores, no contexto das instituições de ensino superior constitui-se como prática o fato de docentes passarem a assumir o papel de gestores e exercer atividades administrativas por indicação ou eleição, sem que os mesmos tenham capacitação específica para essa função. Foi constatado ainda, conforme previu Ahmad (1994), que a principal forma de aprendizagem da função de gestor de curso superior são as práticas informais, tais como, replicar as ações de outros gestores, tentativa e erro.

Foi identificado também, a partir das entrevistas, que os coordenadores são indicados pelos seus pares para assumirem o cargo de coordenação do curso, sendo, normalmente, indicado um professor que faça parte da Comissão Coordenadora do Curso. Entretanto, ocorrem situações em que o professor indicado para o cargo não faça parte da comissão coordenadora e, até mesmo situações em que professores são recém-empossados na universidade assumem o cargo. Tal fato indica o desprestígio que o cargo possui, como podese perceber nas falas dos entrevistados E07 e E01, "ninguém quer ser coordenador de curso e nem chefe de departamento, então é um rodízio mesmo e vai fazendo uma listinha mesmo, você já foi, agora é o outro" (E07), "geralmente é um cargo que muitos professores não querem, a maioria dos professores não querem assumir" (E01). A falta de preparação e o desprestígio do cargo também são bem perceptíveis na resposta do entrevistado E09 ao ser questionado como se tornou coordenador, "No susto! No susto porque não tinha outra pessoa pra assumir, e, nós somos um grupo pequeno, né, e..., é, foi definido: "olha você precisa assumir"... "então ta bom então, vou assumir!" Foi assim."

Dessa forma, percebe-se que não existe a seleção para a ocupação do cargo de coordenação de curso, o que ocorre é a indicação realizada pelos pares que não considera o perfil, a experiência e a vivência na universidade do docente que assumirá o cargo. Vale considerar que, como dito anteriormente, o cargo não é desejado, sendo esse fato uma possível explicação para a falta de critérios no momento da escolha do docente para assumir a função de gestão.

A falta de desprestígio do cargo pode ser explicada por um ponto importante levantado pelos coordenadores que é a acumulação de tarefas que ocorre no exercício da função, uma vez que, os docentes continuam desempenhando as suas funções entendidas como os pilares da universidade, sendo essas, a função de ensino, de pesquisa e de extensão. 
Embora destacado pelos coordenadores de curso que não é necessário uma formação específica em gestão para desempenhar o cargo de coordenação de curso, para eles algumas características atribuídas ao coordenador parecem essenciais à boa gestão do curso, sendo essas, possuir perfil de liderança, ser conciliador, ser proativo, ser organizado, ser flexível, ser bem informado e ser acessível.

A liderança foi uma característica muito evidenciada pelos coordenadores de curso. $\mathrm{Na}$ fala do entrevistado E07 identificamos que a liderança é compreendida como uma característica importante do coordenador, devido à própria função de coordenar as atividades do curso e à necessidade de se relacionar com grupos de alunos e de professores.

A característica de ser conciliador foi atribuída ao coordenador de curso pelos entrevistados, uma vez que o coordenador, segundo entrevistado E04, por se relacionar com diversos grupos, deve buscar entender a perspectiva de cada um e tentar adotar um tom mais conciliatório. Já o coordenador E01 coloca esse tom conciliatório como 'jogo de cintura', pois acredita que para atender os interesses da universidade e dos alunos o coordenador de curso superior precisa ter um bom 'jogo de cintura'.

Ser proativo é outra característica que os coordenadores atribuíram ao gestor de curso superior. A proatividade citada por pelos entrevistados foi no sentido de antever os possíveis problemas que possam vir a surgir no curso e tentar coibi-los ou minimiza-los.

A característica organização também foi muito citada pelos entrevistados, segundo o entrevistado E07, pelo fato de acumular a função de docente com a de coordenador, é necessário que haja muita organização e planejamento das ações, para que sejam estabelecidos prazos e metas, caso contrário o cumprimento das obrigações se torna difícil. $\mathrm{O}$ coordenador E11 associa o termo firmeza à organização ao dizer "as características é ser firme para não se perder nessa corrida administrativa”.

Observa-se que a característica de ser flexível está presente em quase todas as falas dos coordenadores. Na fala do entrevistado E09 fica clara a necessidade do coordenador de curso ser flexível no que diz respeito às várias atividades que surgem no dia a dia, é possível perceber também a necessidade de flexibilidade no sentido de estar preparado para novas situações, conforme observado também na fala do entrevistado E09, “A primeira coisa, a pessoa tem que ser aberta, a pessoa tem que, é, saber lidar com essas situações buscando novas estratégias, né, e às vezes estratégias elas tem”. 
As características até então destacadas sinalizam para uma rotina de gestão tal qual descrita por Mintzberg (2010), principalmente no que se refere a variedade, fragmentação das atividades e as interrupções.

Os coordenadores entrevistados foram unanimes ao dizer que é necessário que o gestor de curso superior tenha conhecimento, esteja sempre atualizado, uma vez que são várias as normas que regem os cursos e essas são constantemente modificadas. O entrevistado E06 aponta que, além do conhecimento técnico do curso, é necessário também, que o gestor tenha o conhecimento de todo o contexto em que o curso está inserido, ou seja, conheça o perfil dos alunos do curso e o perfil dos alunos que deseja formar, dos professores, da estrutura da universidade, do mercado profissional específico do curso. Sobre o entendimento do contexto ao qual está inserido, Mintzberg (2010) entende que processo de gestão o contexto é muito importante, sendo necessário para a função de gerente o conhecimento do contexto específico, e que as tomadas de decisão sejam realizadas com base nesse contexto.

E, por último, mas também muito citada pelos entrevistados, é a característica de ser acessível. Os coordenadores entrevistados entendem que é importante que o gestor de curso superior seja acessível aos alunos e aos professores. Os entrevistados E01 e E11 colocam a acessibilidade com o termo 'saber ouvir', enfatizando ser necessária essa habilidade para que o coordenador consiga atingir os objetivos do curso.

Vale destacar a consideração de Reesor (1995), que argumenta que os docentes geralmente desenvolvem as características de gestão durante o exercício da função e de forma autodirecionada.

\subsection{DESAFIOS DOS GESTORES NA COORDENAÇÃO DE CURSO SUPERIOR}

Os gestores de curso superior enfrentam desafios no desenvolvimento das atividades de gestão. Dessa forma, o objetivo da categoria 'Desafios dos Gestores na Coordenação de Curso Superior' é primeiramente entender como os coordenadores entrevistados compreendem o papel dos gestores para tornar possível destacar os desafios por eles encontram no desenvolvimento deste papel.

Considerando o papel do coordenador que lhe impõe a necessidade de se relacionar com grupos de alunos, professores, técnicos e, ainda, com todos que ocupam cargos na alta gestão da universidade, o coordenador precisa ser conciliador, como já destacado na primeira categoria apresentada. Neste mesmo sentido, Marcon (2008) destaca a característica como relevante para o bom desenvolvimento do curso e para a qualidade das intervenções dos 
egressos desses cursos, uma vez que é necessária uma ação conjunta do coordenador de curso, dos ocupantes dos cargos da alta administração, dos docentes e dos órgãos auxiliares da instituição.

Cinco dos coordenadores entrevistados entendem que o papel do coordenador como o de garantidor de que os objetivos estabelecidos para o curso sejam atingidos. Para esses coordenadores o gestor tem o papel de refletir sobre as questões relacionadas ao curso, ao projeto pedagógico e de verificar a forma adequada de realização do curso.

No decorrer das atividades de gestão de curso superior os coordenadores de curso entrevistados se deparam com desafios, e destacam cinco, os quais são: falta de preparo para o cargo; acúmulo das funções de gestão com a de docência; falta de estrutura; burocracia em excesso; e a relação com os colegas docentes.

A falta de treinamento para o cargo, já destacado na primeira categoria apresentada, foi o desafio mais citado pelos entrevistados, que enfatizam o quanto é difícil assumir uma função sem ter sido preparado/capacitado para ela e, até mesmo, sem compreender bem o papel que deve ser desempenhado.

O segundo desafio mais citado pelos coordenadores de curso entrevistados foi o acumulo de funções do coordenador de curso, uma vez que ao assumir o cargo de coordenador o professor não se isenta das outras funções relacionadas à docência, sendo elas, ministrar aulas, desenvolver pesquisas e projetos de extensão. Dessa forma, os gestores destacaram o quanto é desafiador conciliar as atividades de gestão com as demais funções da carreira docente.

A falta de estrutura também foi um desafio indicado pelos coordenadores entrevistados, principalmente no que se refere à falta de estrutura de pessoal, uma vez que é necessário, segundo os coordenadores, um apoio de secretaria para a coordenação de curso que poderia auxiliar, além das atividades de rotina de interna, também no levantamento de relatórios que auxiliariam as tomadas de decisão do coordenador.

Segundo Reis (2010), o estilo de gestão burocrática é o predominante nas universidades, e o excesso de burocracia foi um desafio apontado pelos entrevistados, pois estes consideram os trâmites processos lentos e com muitas especificidades. E no caso das coordenações de curso, conforme os relatos das entrevistas, compete ao coordenador de curso lidar com a burocracia excessiva e sem o apoio de uma equipe técnica.

E, por fim, outro desafio indicado pelos coordenadores de curso é o relacionamento com os colegas docentes, uma vez que a função de gestão envolve corrigir as falhas que 
possam estar acontecendo e isso implica, em algumas situações, em 'chamar a atenção' de algum colega. Os entrevistados destacaram que existe uma linha tênue em relação à autoridade que pode ser exercida.

Diante o exposto, pode-se perceber que os coordenadores de curso superior não encontram na universidade maneiras para se preparar para o exercício da função e se deparam com desafios e com a falta de estrutura e apoio necessário. Além disso, se deparam com a dificuldade em conciliar as atividades da coordenação com as da docência.

\subsection{SIGNIFICADO DA GESTÃO}

A categoria 'Significado da gestão' foi construída com o objetivo de identificar a compreensão que os coordenadores de curso superior possuem em relação à gestão.

Os coordenadores entrevistados entendem que a gestão do curso superior significa 'pensar o curso', ou seja, que gerenciar um curso implica planejamento e reflexões sobre o curso, sobre o objetivo a ser alcançado e sobre qual o melhor caminho para alcançar esse objetivo.

A gestão do curso superior também foi associada pelos coordenadores entrevistados ao projeto pedagógico do curso, uma vez que, os mesmos entendem que a gestão é entender o projeto pedagógico do curso, fazer com que o projeto pedagógico esteja sempre em conformidade com as diretrizes curriculares estabelecidas em lei e garantir que o mesmo será cumprido.

Ou seja, gerir um curso é colocar em prática um planejamento. Ao colocar a gestão como a forma de refletir sobre o curso e de analisar o projeto pedagógico, a maior parte dos entrevistados apontou a gestão de curso superior como sendo o 'elo de ligação' entre a universidade e os alunos. Vale destacar que, essa compreensão de gestão foi a que mais apareceu nas falas dos entrevistados. A fala do entrevistado E06 sintetiza bem essa compreensão, “é.., a relação entre aluno professor, entre professores, entre alunos, enfim é um processo complexo que envolve a relação entre aluno e professor e a instituição como um todo".

Os gestores de curso superior também associaram a gestão com o ato de lidar com os processos e a burocracia que os envolve. Os processos citados pelos gestores se referem aos processos nos quais os alunos solicitam alguma situação, geralmente situações excepcionais ao regimento interno da universidade e ao projeto pedagógico do curso. Os coordenadores 
colocaram que esses processos ocorrem com muita frequência e que gerencia-los é a gestão de cursos.

Dessa forma, pode-se identificar que a maioria dos coordenadores de cursos superiores entrevistados associou a gestão a quatro pontos específicos, sendo estes: pensar o curso; projeto pedagógico do curso; ligação entre universidade e alunos; e processos/burocracia. $\mathrm{Ou}$ seja, os gestores de curso superior compreendem a gestão de curso como o ato de planejar e implementar o projeto pedagógico do curso, o que envolve se relacionar com os alunos e a administração superior da universidade e lidar com a burocracia envolvida nos processos acadêmicos e organizacionais. Vale ressaltar que, esses pontos foram identificados nas falas de quase todos os entrevistados, porém surgiram naturalmente, não tendo sido préestabelecidos.

\subsection{CARACTERÍSTICAS DA GESTÃO}

A categoria 'Características da Gestão' tem como objetivo discutir como ocorre a gestão de cursos superiores, e para a definição das subcategorias foram utilizadas as características apontadas por Mintzberg (2010), sendo elas: ritmo acelerado, brevidade, variedade e fragmentação das atividades, interrupções, orientação para ação, aspecto informal da informação, natureza lateral das relações e controle implícito.

O ritmo de trabalho do coordenador de curso foi considerado acelerado por todos os entrevistados, uma vez que ele atende as demandas de todos os estudantes do curso, dos professores e da administração superior da universidade.

Vale ressaltar que, todos os coordenadores entrevistados enfatizaram que a rotina de gestão de curso especificamente já é intensa, e ainda, acumulada com as atividades de docentes que os mesmos continuam desempenhando essa rotina se torna ainda mais intensa. Tal fato é constatado ainda na fala do E04, “a gente já tem outras atividades de docente, né, de fazer pesquisa, ensino e extensão e, além disso, você assume a atividade administrativa, que acaba tomando uma parte boa seu dia, então é difícil você conciliar esse ritmo de trabalho". Mintzberg (2010) aponta que vários estudos identificaram que os gerentes trabalham em um ritmo acelerado, no qual suas atividades são variadas, desenvolvidas brevemente e de forma fragmentada. Para o referido autor, o ritmo gerencial intenso é explicado pela sua natureza inerentemente aberta, não sendo possível identificar o momento em que se dá o encerramento do trabalho gerencial. 
Os gestores de curso desenvolvem várias atividades, em um ritmo muito acelerado e com brevidade das ações, assim, pode-se perceber que o trabalho do gestor é fragmentado, sendo marcado por interrupções e descontinuidades. O entrevistado E11 coloca de forma bem objetiva essa questão, "Você não consegue ter uma rotina. Eu faço uma agenda semanal para mim, nunca consigo cumprir, porque as demandas o tempo todo são interrompidas e não tem jeito".

A característica da gestão de ser orientada para ação é bem característica do trabalho do coordenador de curso. É possível perceber que as atividades de planejamento e reflexões ficam em segundo plano. O que podemos perceber é que as características citadas anteriormente, como fragmentação, ritmo intenso e brevidade das ações, levam à falta de cumprimento do que foi planejado ou, até mesmo, à falta de planejamento. Os coordenadores entrevistados relataram que possuem uma 'agenda' de atividade, mas que nem sempre é possível cumpri-la. Dessa forma, pode-se identificar que a gestão realizada pelos coordenadores de curso segue a característica da gestão apontada por Mintzberg (2010), pois as ações são realizadas na medida em que aparecem, sendo pouco tempo despendido para os planejamentos e reflexões, conforme o relato do E09, que considera que a gestão de curso é 'apagar incêndios'.

Perguntados sobre como ocorre a comunicação na gestão de cursos superiores, a maioria dos entrevistados respondeu que a maior parte da comunicação se dá informalmente, conforme salientado por Mintzberg (2010). A partir da fala dos entrevistados é possível perceber que a maior parte das comunicações ocorre por email, e, um ponto bem enfatizado pelos gestores, é que a comunicação ocorre na maior parte das vezes pessoalmente. Muitos alunos e professores procuram o coordenador de curso para resolverem assuntos diversos, sendo o contato direto muito importante e valorizado pelos entrevistados.

Mintzberg (2010) aponta o acesso pessoal como uma característica importante da comunicação na atividade de gestão, segundo ele é importante que o gestor conheça bem o contexto em que está inserido e as pessoas com as quais está lidando. Diante dessa consideração de Mintzberg (2010), pode-se perceber que os coordenadores de curso superior entrevistados tem essa preocupação em conhecer o contexto do curso, conhecer o projeto pedagógico, as diretrizes curriculares, se informar sobre o mercado de trabalho, de conhecer o perfil dos alunos do curso, e mais ainda, de conhecer os alunos individualmente.

A relação lateral das relações é também uma característica da gestão apontada por Mintzberg (2010), uma vez que o gestor se relaciona com várias pessoas diferentes. Na gestão 
de curso é facilmente detectada essa relação lateral do coordenador de curso, ele lida diretamente com os alunos, com os professores, com os técnicos administrativos e com a administração superior da universidade. Assim, o coordenador de curso pode ser considerado uma 'ampulheta', como indica Mintzberg (2010) ao falar de gestão, pois o coordenador de curso é o elo de ligação entre a universidade (administração superior, professores e técnicos administrativos) e os alunos. Tal situação é verificada na fala do E11, "Tendo que lidar com demanda de estudantes, demanda de professores, apaziguar conflitos, fazer interlocução com a administração, é o tempo todo isso".

Diante todo o exposto, é possível perceber que todas as características da gestão apontadas por Mintzberg (2010) se reproduzem na forma como os coordenadores gerenciam os cursos superiores.

\section{CONSIDERAÇÕES FINAIS}

O presente trabalho teve como objetivo principal compreender os significados e as características de gestão para os coordenadores de curso superior. Para tanto, foram utilizados como base os ensinamentos de Henry Mintzberg (2010), com o entendimento de que o significado da gestão para os coordenadores passa pela análise da compreensão da gestão e das características dos gestores, assim como dos desafios enfrentados por estes.

O que se percebe é que os coordenadores entendem a gestão de curso superior como sendo o reflexo dos objetivos do curso, como o ato de gerenciar o projeto pedagógico do curso, como a articulação existente entre os alunos e a administração superior da universidade e como o processo burocrático e de organização que envolve o curso. Ou seja, não se trata de uma gestão que sofre influência de pressões competitivas, tecnologia e outras originadas do ambiente externo, mas sim voltada a atender um plano de ação já estabelecido e aprovado dentro da instituição.

Percebe-se que o significado e as características da gestão para os coordenadores de curso superior se tratam de uma reprodução das observações realizadas por Henry Mintzberg (2010). O que ocorre é uma prática de gestão marcada pelo ritmo implacável, pela fragmentação e interrupção das atividades e pela preferência pela comunicação informal e oral.

Para além das considerações apresentadas por Mintzberg (2010), no que se refere ao trabalho do gerente, que diz respeito ao ritmo acelerado, no qual as atividades são variadas e desenvolvidas de forma fragmentada, os gestores públicos, coordenadores de cursos, são 
obrigados a agir em observância as normas legais e submetidos a pressões referentes às sanções impostas. São coordenadores que aprendem a serem gestores com a prática e não contam com políticas institucionais de incentivo para a preparação e para o exercício de sua função. Assumem as novas tarefas, que inclui a gestão de pessoas, sem abdicar de suas outras atividades relacionadas ao ensino, a pesquisa e a extensão.

Uma vez coordenadores, percebem a necessidade de trabalhar as suas características para exercer a liderança e colocar em prática o projeto pedagógico, tais como a capacidade de relacionamento interpessoal, o perfil conciliador e proativo, a disciplina, a flexibilidade, a atualização e a acessibilidade. Ao tempo que também se conscientizam de que se trata de um cargo de desprestígio na instituição.

Os coordenadores se deparam com o desafio de conciliar o que parece inconciliável, o exercício das atividades da docência com o cargo de gerente universitário. Embora permaneçam, lidam com a falta de políticas de incentivos, tanto para a sua qualificação quanto para colocar as ações em curso. Eles não contam com os recursos humanos e materiais necessários e se reinventam a cada dia, identificando e superando limitações, pessoais e do cargo. Lidam com as adversidades, com a consciência da impossibilidade de se fazer cumprir as agendas de trabalho e se assumem como "gestores bombeiros", apagadores de incêndios.

O que se observa com os depoimentos é a necessidade de valorizar o cargo de coordenador dentro da instituição de ensino e proporcionar apoio aos que aceitam o desafio de cuidar do projeto pedagógico dos cursos e lidar com os seus grupos de interesse. Necessidade de uma política de incentivo para superar as limitações e os desafios identificados pelos "gerentes de curso" para colocar em prática um projeto pedagógico e, ainda, manter os índices de produtividade exigidos aos professores universitários.

O que se nota nesta pesquisa é o que o trabalho do coordenador é altamente reativo às ações e os desafios sinalizam para o risco em termos de saúde ocupacional. O coordenador, embora esteja gerindo a formação do profissional do futuro, parece solto numa estrutura burocrática e política, o que precisa ser mudado. Sinaliza-se para a necessidade de outras pesquisas que abordem o tema, tendo em vista a importância dos coordenadores dentro das universidades. 


\section{AGRADECIMENTOS}

Agradecemos aos coordenadores de curso superior da universidade federal estudada, uma vez que participaram das entrevistas, contribuindo muito com o estudo ao fornecerem informações essenciais para a análise.

\section{REFERÊNCIAS BIBLIOGRÁFICAS}

AHMAD, Z. A. Chief academic officers as learners: adult learning patterns within on organizational context. Dissertação (Mestrado em Educational Policy and Leadership) Northen Illinois University, Illiniois, 1994.

ALBERTI, V. Manual de História Oral. 3 ed.Rio de Janeiro: editora FGV, 2005.

ALVES, L. Competências individuais em organizações do conhecimento: um estudo nas instituições particulares e comunitárias de Santa Catarina. Dissertação (Mestrado em Engenharia e Gestão do Conhecimento), 2009.

BARDIN, L. Análise de conteúdo. Lisboa, edições 70, 1997.

BOTOMÉ, S. P.; KUBO, O. Gestão da universidade: experiências de "pés no chão". Revista Interação em Psicologia, Curitiba, v. 9, n.1, p.187-189, 2005.

BAUER, M. W.; GASKELL, G. Pesquisa qualitativa com texto: imagem e som: um manual prático. 7 ed. Petrópolis, RJ: vozes, 2008.

CAMARgOS, M. A., FERREIRA, A. R.; CAMARGOS, M. C. S. Percepção, atuação, autonomia e condição de trabalho de coordenadores de curso de administração de IES do Estado de Minas Gerais. Revista de Gestão, v. 17, n. 3, p. 285-296, jul./ set., 2010.

CAMPOS, D. C. da S.; Competências gerenciais dos pró-reitores em uma instituição de ensino superior: Um estudo de caso na Universidade Federal de Viçosa. 2007.157f.

Dissertação (Graduação em Administração). Programa de Pós-Graduação em Administração Universidade Federal de Viçosa, Viçosa. 2007.

ÉSTHER, A. B. As competências gerenciais dos reitores de universidades federais em Minas Gerais: a visão da alta administração. CADERNOS EBAPE. BR, Rio de Janeiro, pp. 648-667, Jul. 2011.

FLICK, U.; tradução: COSTA, R. C. Qualidade na pesquisa qualitativa. Porto Alegre: Artmed, 2009.

FREITAS, S. M. de. História oral: possibilidades e procedimentos. 2 ed. SP: Associação Editorial Humanitas, 2006.

GHOSGAL, S. \& BRUCH, H. Going beyong motivation to the power of volition. MIT Sloan Management Review, 44(3), 51-57, 2003. 
GOMES, O. F; GOMIDE, T. R; GOMES, M. A. N; ARAÚJO, D. C; MARTINS, S; FARONI, W. Sentidos e Implicações da Gestão Universitária para os Gestores Universitários. Revista GUAL, Florianópolis, v. 6, n. 4, p. 234-255, Edição Especial, 2013.

HOMBERG, I. \& TYRSTRUP, M. (2010). Well then - What now? Na everyday approach to managerial leadership. Leadership, 6(4), 353-372.

KWASNIDA, E. L. Introdução a Administração. 6. ed. Atlas: São Paulo, 2009.

MAGAlHÃES, E. M. de; OLIVEIRA, A. R. de; CUNHA, N. R. da S; LIMA, A. A. T. de F. de C.; CAMPOS, D. S; SILVEIRA, C. A política de treinamento dos servidores técnicoadministrativos da Universidade Federal de Viçosa (UFV) na percepção dos treinados e dos dirigentes da instituição. Revista de Administração Pública, Rio de Janeiro p. 55-86, Jan./fev, 2010.

MARCON, S. R. A. Comportamentos que constituem o trabalho de um coordenador de curso de graduação. Tese (Doutorado em Psicologia) -Universidade Federal de Santa Catarina, Florianópolis, 2008.

MARRA, A. V.; MELO, M. C. de O. L. A Prática Social de Gerentes Universitários em uma Instituição Pública. RAC, v. 9, n. 3, Jul./Set: 09-31. 2005.

MEYER JUNIOR, V. Teoria e Prática da gestão universitária. Cadernos: Centro Universitário São Camilo, São Paulo, v. 4, n.1, p. 49-59, jan./jun., 1998.

MINTZBERG, H. Managing: Desvendando o dia a dia da gestão. Porto Alegre: Bookman, 2010, 304p.

PALMEIRAS, J. D. B.; SZILAGYI, R. S. Perfil e competências necessários para um coordenador de curso na percepção dos gestores e funcionários de uma IES. In: COLÓQUIO INTERNACIONAL SOBRE GESTÃO UNIVERSITÁRIA NA AMÉRICA DO SUL, 11., 2011, Florianópolis, Santa Catarina.

REIS, C. Z. T. Estágios da Institucionalização do modelo de alocação de recursos orçamentários das universidades federais brasileiras. Dissertação de mestrado, Universidade Federal de Viçosa, 2011.

REESOR, L. Becoming na academic administrator:a case stydy approach. Tese (Doutorado em Educational Policy and Leadership)-University of Wisconsin, Whitewate, 1995.

SANTANA, L. L. e S.; CUNHA, SILVEIRA, N. R. da; OLIVEIRA, A. R. de;. Características de liderança: qual a percepção de gestores públicos?. REUNA, Belo Horizonte, v.15, n.2, p. 13-26, mai. Ago, 2010.

SILVA, J. J.; A auditoria interna da UFPE: A percepção dos gestores num contexto de avaliação de desempenho e resultados. 2009.116f. Tese (Doutorado em Ciências Contábeis), Universidade Federal de Pernambuco, Pernambuco. 2009. 
TENGBLAD, S. Is there a 'New Managerial Work'? A comparison with Henry Mintzberg's classic study 30 years later. Journal of Management Studies, 43(7), 1437-1461, 2006.

VIANA, S. M. N. Perfil e ações gerenciais dos (as) dirigentes dos cursos de enfermagem dos centros universitários e universidades do estado de Minas Gerais. Dissertação

(Mestrado em Enfermagem) -Universidade Federal de Minas Gerais, Belo Horizonte, 2006.

ZABALZA, M. Ensino universitário: seu cenário e seus protagonistas. Porto Alegre: Artmed, 2004. 